http://jmscr.igmpublication.org/home/

ISSN (e)-2347-176x ISSN (p) 2455-0450

crossref DOI: https://dx.doi.org/10.18535/jmscr/v7i10.162

Journal Of Medical Science And Clinical Research

IGM Publication

An official Publication of IGM Publication

\title{
A Prospective Study of Dexmedetomidine to Attenuate Haemodynamic Responses to Endotracheal Intubation
}

\author{
Authors \\ Dr Md. Arshad Imam ${ }^{1}$, Dr Md. Shariq Sayeed ${ }^{2}$ \\ ${ }^{1}$ Professor, Dept. of Anesthesia, KMC, Katihar \\ ${ }^{2}$ Asst. Prof, Dept. of Anesthesia, KMC, Katihar
}

\section{Introduction}

Since the time of inception of endotracheal anesthesia in the last quarter of $19^{\text {th }}$ century, endotracheal intubation has become one of the very common procedures performed in the practice of anesthesia. We have a novel drug from the family of alpha-2 adrenergic agonist, Dexmedetomidine, which is a D-isomer of medetomidine. It is more specific for alpha-2 adrenergic receptor and shorter acting than clonidine. In recent study this drug has been shown to have clinically significant effects on anesthetic requirements, hemodynamic responses induced by anesthesia and surgery in patients. This study is an attempt to assess the safety and efficacy of dexmedetomidine in attenuating hemodynamic responses to laryngoscopy and endotracheal intubation.

\section{Aims and Objectives}

To assess the safety and efficacy of dexmedetomidine in attenuating hemodynamic responses to laryngoscopy and endotracheal intubation in a single peroperative dose of i.v. dexmedetomidine.

The primary objective would be to assess:

1) The changes in heart rate, systolic, diastolic and mean arterial pressures during and after endotracheal intubation.
2) Effect of dexmedetomidine in attenuating these cardiovascular responses.

\section{Material and Methods}

Injection Dexmedetomidine $0.5 \mathrm{ml}$ containing 50 microgram/ml in $100 \mathrm{ml}$ normal saline bottle.

It was a prospective, double blinded, parallel group, randomized, placebo-controlled clinical trial of dexmedetomidine for attenuating hemodynamic responses to laryngoscopy and endotracheal intubation.

IEC approval taken with informed consent.

Study was conducted at Katihar Medical College, Katihar in the department of anesthesiology in the operation theatre.

Sample size was 100.50 patients as cases and 50 patients as control.

\section{Inclusion Criteria}

Patients undergoing elective surgery under general anesthesia, ASA grade I \& II, age group 20-50 years and patients of both the sexes were included.

\section{Exclusion Criteria}

Patient's refusal, emergency surgery, morbid obesity (BMI> 30kg/m2), any hepatic impairment, renal compromise, DM on insulin, pregnant and lactating women, predicted difficult intubation, intubation attempt lasting longer than 20 seconds. 


\section{Result}

Group C: patients received $100 \mathrm{ml} \mathrm{NS}$, infused over 15 minutes before induction.

Group D: patients received dexmedetomidine 0.5 microgram/kg body weight mixed in $100 \mathrm{ml} \mathrm{NS}$, infused over $15 \mathrm{~min}$ before induction.

\section{Sex Distribution:}

\begin{tabular}{|l|c|c|c|c|c|}
\hline \multirow{2}{*}{ Sex } & \multicolumn{2}{|c|}{ Group C } & \multicolumn{2}{c|}{ Group D } & \multirow{2}{*}{ REMARKS } \\
\cline { 2 - 5 } & NO. & $\%$ & NO. & $\%$ & \\
\hline Male & 22 & 44 & 19 & 38 & P $>0.05$ \\
\hline Female & 28 & 56 & 31 & 62 & \\
\hline
\end{tabular}

Age Distribution: the highest age in the study was 59 years and the lowest was 20 years. The majority of the patients were in the age group 2040 years.

Weight Distribution: the body weight of the patients ranged from $44 \mathrm{~kg}$ to $72 \mathrm{~kg}$.

ASA grading: majority of the patients were of the ASA grade I $(79 \%)$, only $21 \%$ of the patients were of ASA grade II.
Heart rate at different time interval:

T1 basal level. Group C was 82.82 and group D was 86.74 with $\mathrm{SD} \pm 13.37$ and 15.37 respectively.

T2 preinduction. Group C was 87.52 and group D was 76.00 with $\mathrm{SD} \pm 12.11$ and 14.77 respectively.

I laryngoscopy and intubation. Group C was 115.86 and group $\mathrm{D}$ was 87.82 with $\mathrm{SD} \pm 13.12$ and 15.41 respectively.

I1 1 minute after intubation. Group C was 108.28 and group $\mathrm{D}$ was 87.18 with $\mathrm{SD} \pm 11.55$ and 14.61 respectively.

I2 2 minutes after intubation. Group C was 102.74 and group D was 87.18 with $\mathrm{SD} \pm 10.87$ and 14.37 respectively.

I3 3 minutes after intubation. Group C was 97.82 and group D was 82.72 with $\mathrm{SD} \pm 10.81$ and 13.90 respectively.

I4 4 minutes after intubation. Group C was 93.62 and group $\mathrm{D}$ was 80.28 with $\mathrm{SD} \pm 11.21$ and 13.21 respectively.

I5 5 minutes after intubation. Group C was 89.98 and group $\mathrm{D}$ was 77.76 with $\mathrm{SD} \pm 11.72$ and 12.90 respectively.

Systolic blood pressure at different interval of time:

\begin{tabular}{|l|c|c|c|c|c|c|c|c|}
\hline TIME & $\mathrm{T} 1$ & $\mathrm{~T} 2$ & $\mathrm{I}$ & $\mathrm{I} 1$ & $\mathrm{I} 2$ & $\mathrm{I} 3$ & $\mathrm{I} 4$ & $\mathrm{I}$ \\
\hline GROUP C & 125.60 & 123.78 & 147.66 & 142.02 & 136.52 & 134.44 & 131.96 & 129.96 \\
& \pm 8.55 & \pm 8.43 & \pm 8.38 & \pm 8.25 & \pm 7.80 & \pm 7.62 & \pm 8.40 & \pm 9.37 \\
\hline GROUP D & 127.56 & 120.72 & 137.64 & 132.24 & 127.34 & 122.56 & 119.82 & 117.26 \\
& \pm 8.11 & \pm 8.20 & \pm 7.18 & \pm 7.61 & \pm 7.55 & \pm 7.38 & \pm 7.55 & \pm 7.40 \\
\hline
\end{tabular}

In group $\mathrm{C}$ the mean diastolic arterial pressure had significant increase at preinduction. At laryngoscopy the mean diastolic arterial pressure rose to very high level $16.51 \%$ above base line value. In group $\mathrm{D}$ the mean diastolic arterial pressure at preinduction was not significant. At laryngoscopy it increased above base line value by $8.46 \%$.

\section{Discussion}

Patients of both the groups received tablet diazepam $10 \mathrm{mg}$ and pantoprazole $40 \mathrm{mg}$ orally night before surgery. Out of 100 patients studied
41 were male and 59 were female. Sex distribution was statistically not significant between the two groups. The oldest patients was of 59 years of age and the youngest was 20 years of age. Age 20-40 years comprised of maximum number of patients i.e. 69. The weight of the patients ranged from $44 \mathrm{~kg}$ to $72 \mathrm{~kg}$ with maximum weighing between $50-60 \mathrm{~kg}$. Majority of the patients belonged to ASA grading I. There was a rise in the mean heart rate in group $\mathrm{C}$ during laryngoscopy and endotracheal intubation from $82.82 \pm 13.37(\mathrm{~T} 1)$ to $115.86 \pm 13.12(\mathrm{I})$. This rise was statistically very highly significant $(\mathrm{p}<0.001)$. 
The mean heart rate till $5^{\text {th }}$ minutes after intubation was higher than the basal value which were similar to the findings of Menda et al, Kenya et al and Sulaiman et al. In group D there was a decrease in mean heart rate at preinduction from basal value of $86.74 \pm 15.37$ (T1) to $76.00 \pm 14.77$. This fall in the mean heart rate was very highly significant. ( $p<0.001)$. in the present study when group $\mathrm{C}$ and $\mathrm{D}$ were compared, Dexmedetomidine was found to be successful in attenuating the tachycardia response, as the statistical significance of the difference in the mean heart rate between the two groups at all intervals of time after intubation was very highly significant $(p<0.001)$.

\section{Summary and Conclusion}

In this present study, consisting of 100 patients between the age group of 20-60 years, belonging to ASA grade I and II, scheduled for elective surgical procedure under general anesthesia. Patients were randomly divided into 2 groups of 50 each. Patient of group $\mathrm{C}$ received placebo and group D received Dexmedetomidine.

Hemodynamic response like heart rate, systolic arterial pressure and diastolic arterial pressure were recorded on arrival in OT before giving any drug and at preinduction. There is a much rise in heart rate in group $\mathrm{C}$ while in group $\mathrm{D}$ the rise in heart rate was nominal and insignificant at and following laryngoscopy and endotracheal intubation. The rise of SAP in dexmedetomidine group was much less in comparison to control group. There was significant increase in diastolic arterial pressure, but it was less significant in group $\mathrm{D}$. The increase in mean arterial pressure was found in both the groups but it was less profound in dexmedetomidine group. The cardiovascular responses to laryngoscopy and endotracheal intubation are potentially harmful and methods to obviate these responses have been particularly useful in vulnerable and critically ill patients. Single shot i.v. dexmedetomidine is simple, effective and acceptable mean to attenuate the pressure response to laryngoscopy and endotracheal intubation. However the study has to be continued in more no. of patients and also in patients with hypertension and ischemic heart disease for further evaluation.

\section{Bibliography}

1. Derbishire DR, Chmeilewski A, Feli D, Vater M, Achola K and Smith G. plasma catecholamine responses to tracheal intubation. $\mathrm{Br} \mathrm{J}$ anesthesia 1983;55[9] :855-860

2. Singh O. circulatory response to endotracheal intubation in hypertensive patients. Ind J anesthesia 1999;37[1]:4-7.

3. Reddy SV, Balaji D, Ahmed SN. Dexmedetomidine versus esmolol to attenuate the hemodynamic response to laryngoscopy and tracheal intubation: A randomized double-blind clinical study. Int J App Basic Med Res. 2014;4:95-100.

4. Williams P, Waewick R. Gray's anatomy. $27^{\text {th }}$ edition. Edinburgh, Churchill Livingstone, 1989;1249-1259.

5. Sulaiman S, Vakamudi $M$ and Gandham $\mathrm{R}$. the effects od dexmedetomidine on attenuation of stress response to endotracheal intubation in patients undergoing elective off pump coronary artery bypass grafting. Annals od cardiac anesthesia 2012;15[1]:39-43. 